\title{
Brain ischemia alters platelet ATP diphosphohydrolase and 5 '-nucleotidase activities in naive and preconditioned rats
}

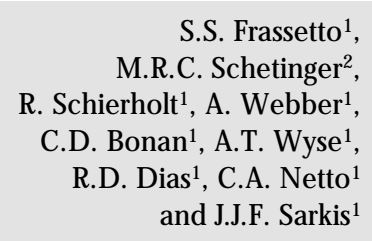

S.S. Frassetto ${ }^{1}$,

M.R.C. Schetinger ${ }^{2}$,

R. Schierholt ${ }^{1}$, A. W ebber ${ }^{1}$,

C.D. Bonan ${ }^{1}$, A.T. Wyse ${ }^{1}$,

R.D. Dias ${ }^{1}$, C.A. N etto ${ }^{1}$

and J.J.F. Sarkis ${ }^{1}$

\author{
1Departamento de Bioquímica, Instituto de Ciências Básicas da Saúde, \\ Universidade Federal do Rio Grande do Sul, Porto Alegre, RS, Brasil \\ ${ }^{2}$ Setor de Bioquímica, Departamento de Q uímica, \\ Centro de Ciências N aturais e Exatas, Universidade Federal de Santa Maria, \\ Santa Maria, RS, Brasil
}

\section{Correspondence \\ C.A. N etto \\ Departamento de Bioquímica ICBS, UFRGS \\ Rua Ramiro Barcelos, 2600 (anexo) \\ 90035-003 Porto Alegre, RS \\ Brasil \\ Fax: + 55-51-316-5535 \\ E-mail: alexneto@ vortex.ufrgs.br \\ Research supported in part by FINEP and CNPq. S.S. Frassetto was the recipient of a CAPES fellowship.}

Received O ctober 8, 1999 Accepted July 27, 2000

\section{Abstract}

The effects of transient forebrain ischemia, reperfusion and ischemic preconditioning on rat blood platelet ATP diphosphohydrolase and 5'nucleotidase activities were evaluated. Adult Wistar rats were submitted to 2 or $10 \mathrm{~min}$ of single ischemic episodes, or to $10 \mathrm{~min}$ of ischemia 1 day after a 2-min ischemic episode (ischemic preconditioning) by the four-vessel occlusion method. Rats submitted to single ischemic insults were reperfused for $60 \mathrm{~min}$ and for 1, 2, 5, 10 and 30 days after ischemia; preconditioned rats were reperfused for $60 \min 1$ and 2 days after the long ischemic episode. Brain ischemia ( 2 or $10 \mathrm{~min}$ ) inhibited ATP and ADP hydrolysis by platelet ATP diphosphohydrolase. On the other hand, AMP hydrolysis by 5 '-nucleotidase was increased after 2 , but not 10, min of ischemia. Ischemic preconditioning followed by 10 min of ischemia caused activation of both enzymes. Variable periods of reperfusion distinctly affected each experimental group. Enzyme activities returned to control levels in the 2-min group. However, the decrease in ATP diphosphohydrolase activity was maintained up to 30 days of reperfusion after 10-min ischemia. 5'-Nucleotidase activity was decreased $60 \mathrm{~min}$ and 1 day following 10-min ischemia; interestingly, enzymatic activity was increased after 2 and 5 days of reperfusion, and returned to control levels after 10 days. Ischemic preconditioning cancelled the effects of 10-min ischemia on the enzymatic activities. These results indicate that brain ischemia and ischemic preconditioning induce peripheral effects on ecto-enzymes from rat platelets involved in nucleotide metabolism. Thus, ATP, ADP and AMP degradation and probably the generation of adenosine in the circulation may be altered, leading to regulation of microthrombus formation since ADP aggregates platelets and adenosine is an inhibitor of platelet aggregation.
Key words

- Brain ischemia

- Ischemic preconditioning

- Rat platelets

- ATP diphosphohydrolase

- 5'-Nucleotidase 


\section{Introduction}

Studies on the biological role of ATP, ADP, AMP and adenosine in extracellular metabolism suggest that these compounds control distinct, and often opposite metabolic processes. Therefore, the activity of enzymes that regulate their concentration is of great biological importance. Ecto-ATP diphosphohydrolases (apyrases, EC 3.6.1.5) catalyze the hydrolysis of both di- and triphosphate nucleosides. In the case of ATP and ADP hydrolysis, the reaction products are AMP and inorganic phosphate (1). Ecto5'-nucleotidases (EC 3.1.3.5) hydrolyze AMP to adenosine. The ubiquity and distribution of ATP diphosphohydrolases and 5'-nucleotidases suggest that these enzymes might play an important role in the regulation of nucleotide and adenosine levels $(2,3)$.

Platelets express ecto-ATP diphosphohydrolase $(4,5)$ and ecto-5'-nucleotidase (6) activities. In previous reports, our group described the presence of ATP diphosphohydrolases in human blood platelets (7), synaptosomes $(8,9)$, rat brain synaptic plasma membranes (10) and rat heart sarcolemmal fractions (11). With respect to the vascular system, it was suggested that a possible physiological role for ATP diphosphohydrolase is its participation in an "enzymatic chain", together with 5 '-nucleotidase, for the complete hydrolysis of ATP to adenosine. Adenine nucleotides and nucleosides may play a role in the regulation of vascular tone and platelet aggregation since ATP and ADP are vasoactive and plateletactive nucleotides $(12,13)$, respectively, and adenosine is a vasodilator (14) and an inhibitor of platelet aggregation (15). It was thus suggested that activation of ATP diphosphohydrolase and 5'-nucleotidase might result in inhibition of platelet aggregation, vascular tone control and microthrombus formation $(4,5)$.

It is known that brain ischemia causes cell death of vulnerable neurons (16), but such injury is markedly limited when ischemic preconditioning is induced (17). It was demonstrated that a brief ischemic episode (lasting 1 or $2 \mathrm{~min}$ ) that causes no cell death induces tolerance to longer ischemic episodes (10-min ischemic episode) inflicted 24 or $48 \mathrm{~h}$ later $(16,17)$ resulting in only $30 \%$ cell death in the hippocampal $\mathrm{CA}_{1}$ pyramidal cells (as compared to $90 \%$ neuronal death after the 10-min ischemic episode). This phenomenon of induced tolerance can also be produced for myocardial ischemia, but despite extensive investigation the mechanisms underlying ischemic preconditioning are not clearly established $(18,19)$. Along with evidence that the injury-limiting effect of myocardial preconditioning can be primarily attributable to adenosine (19), Schetinger et al. (20) have demonstrated activation of synaptosomal ATP diphosphohydrolase from the hippocampus of rats tolerant to brain ischemia. Interestingly, human studies report that patients with ischemic cerebrovascular disease present vascular platelet activation and microthrombus formation $(21,22)$.

Since a) preconditioning to brain ischemia changes activity of hippocampal ATP diphosphohydrolase in rats (20) and b) patients suffering from cerebrovascular disease show platelet activation $(21,22)$, we decided to investigate whether preconditioning to brain ischemia would alter platelet ATP diphosphohydrolase and 5'-nucleotidase activities in the rat. Our hypothesis is that ischemic preconditioning, known to cause cellular protection, could alter these enzymatic activities leading to a possible increase in peripheral ADP degradation and adenosine formation, and the consequent regulation of microthrombus formation and vascular tissue oxygen supply.

\section{Material and Methods}

\section{Material}

Nucleotides were obtained from Sigma Chemical Co. (St. Louis, MO, USA). Sepharose 2B was obtained from Pharmacia 
(Uppsala, Sweden) and was de-aerated in a vacuum flask before packing in a polyethylene column. All other reagents were of analytical grade. Polyethylene or siliconized labware was used for all platelet isolation and incubation procedures.

\section{Brain ischemia and reperfusion}

Male Wistar rats from our breeding stock, weighing 180-200 g, were maintained on a 12-h light/dark cycle in a constant temperature room. Forebrain ischemia was produced by the 4 -vessel occlusion (4-VO) method $(20,23)$. Briefly, the vertebral arteries were electrocoagulated through the alar foramina on the first cervical vertebra under halothane anesthesia, and silastic ties were inserted around the carotids and brought to the surface. Twenty-four hours later the ties were tightly clamped for 2 or $10 \mathrm{~min}$. Variable periods of reperfusion were allowed: $60 \mathrm{~min}$, and 1, 2, 5, 10 and 30 days. The preconditioned group (double-ischemic rats) received 10 -min ischemia 1 day after a 2 -min ischemic episode (referred to as $2^{\prime}+10^{\prime}$ ), followed by $60 \mathrm{~min}, 1$ and 2 days of reperfusion. Rats that did not lose the righting reflex or that convulsed during the ischemia or reperfusion periods were discarded. Shamoperated (animals with vertebral electrocoagulation and carotid preparation, but no carotid occlusion) and intact rats were used as controls. The 4-VO ischemia in the awake rat was the experimental model employed to avoid the use of any drug during ischemic event(s) that might influence neural outcome (i.e., the neuroprotective effect of anesthetics). All animal use procedures were approved by the local Animal Care Committee.

\section{Platelet isolation}

Rats were killed by decapitation and peripheral blood was collected into citrated tubes. Platelets were isolated as described by Hantgan (24). The intact platelets were sepa- rated from plasma by gel filtration through a $1.5 \times 7 \mathrm{~cm}$ Sepharose 2B column. The column was equilibrated with a buffer consisting of $140 \mathrm{mM} \mathrm{NaCl}, 2.5 \mathrm{mM} \mathrm{KCl}, 10 \mathrm{mM}$ HEPES, $5.5 \mathrm{mM}$ dextrose, $0.2 \mathrm{mM}$ EGTA, and $0.05 \mathrm{~g} \%$ azide, $\mathrm{pH}$ 6.8. Platelets were eluted with the same buffer at room temperature, $0.5-\mathrm{ml}$ fractions were collected and the tubes containing platelets, as determined visually, were used for the experiments. Platelets were prepared fresh daily.

\section{Determination of ATP diphosphohydrolase and 5'-nucleotidase activities}

ATP and ADP hydrolysis by platelet ATP diphosphohydrolase was carried out in a medium containing $120 \mathrm{mM} \mathrm{NaCl}, 5.0 \mathrm{mM}$ $\mathrm{KCl}, 6.0 \mathrm{mM}$ glucose, $5.0 \mathrm{mM} \mathrm{CaCl}_{2}$, and 50 $\mathrm{mM}$ Tris- $\mathrm{HCl}$ buffer, $\mathrm{pH} 7.5$, as previously described (4). The enzyme reaction was started by the addition of ATP or ADP to a final concentration of $0.5 \mathrm{mM}$. Platelet 5'nucleotidase activity was assayed as described by Nishio et al. (25). AMP hydrolysis was carried out in a medium containing $134 \mathrm{mM} \mathrm{NaCl}, 5.0 \mathrm{mM}$ glucose, $1.5 \mathrm{mM}$ $\mathrm{MgCl}_{2}$ and $15 \mathrm{mM}$ Tris-HCl buffer, $\mathrm{pH}$ 7.4. The enzyme reaction was started by the addition of AMP to a final concentration of 2.0 $\mathrm{mM}$. Incubation times (60 min for ATP diphosphohydrolase and $120 \mathrm{~min}$ for 5'-nucleotidase) and protein concentration (0.1-0.15 $\mathrm{mg} / \mathrm{ml}$ ) were chosen in order to ensure the linearity of the enzyme reactions. The reactions were stopped by the addition of trichloroacetic acid to a final concentration of $5 \%$ $(w / v)$. Controls with the enzyme preparation after the addition of trichloroacetic acid were used to correct for nonenzymatic hydrolysis of the substrate. All assays were run in duplicate with appropriate controls. Released phosphate (Pi) was measured by the method of Chan et al. (26). A unit of activity (U) is expressed as $1.0 \mathrm{nmol}$ of $\mathrm{Pi}$ released/min at $37^{\circ} \mathrm{C}$. Specific activities are defined as $\mathrm{U} / \mathrm{mg}$ protein (nmol Pi released min $^{-1} \mathrm{mg}$ protein ${ }^{-1}$ ). 
Only one platelet preparation from each rat was used for the enzymatic assays described below.

\section{Protein determination}

Protein was determined by the Coomassie blue method (27) with bovine serum albumin used as standard.

\section{Statistical analysis}

Data were analyzed by one-way and twoway analysis of variance. Post-hoc tests included the Duncan procedure for multiple intergroup comparisons. P values lower than 0.05 were considered to be significant.

\section{Results}

\section{Effect of single episodes of brain ischemia on platelet ATP diphosphohydrolase and 5'-nucleotidase activities}

Control ATPase and ADPase specific

Figure 1 - Activity of platelet ATP diphosphohydrolase (ATPase activity) after brain ischemia ( 2 and $10 \mathrm{~min}$ ) and ischemic preconditioning $\left(2^{\prime}+10^{\prime}\right)$ followed by reperfusion. Results are expressed as percentage of control activity. Data are reported as means \pm SEM for 6 to 8 different platelet preparations assayed in duplicate. Sham value for ATPase activity was $103.2 \pm$ $6.4 \%(\mathrm{~N}=8) . * \mathrm{P}<0.05$ compared to control group. ${ }^{+} \mathrm{P}<0.05 \mathrm{com}$ pared to the $2^{\prime}+10^{\prime}$ group without reperfusion (analysis of variance and Duncan test).

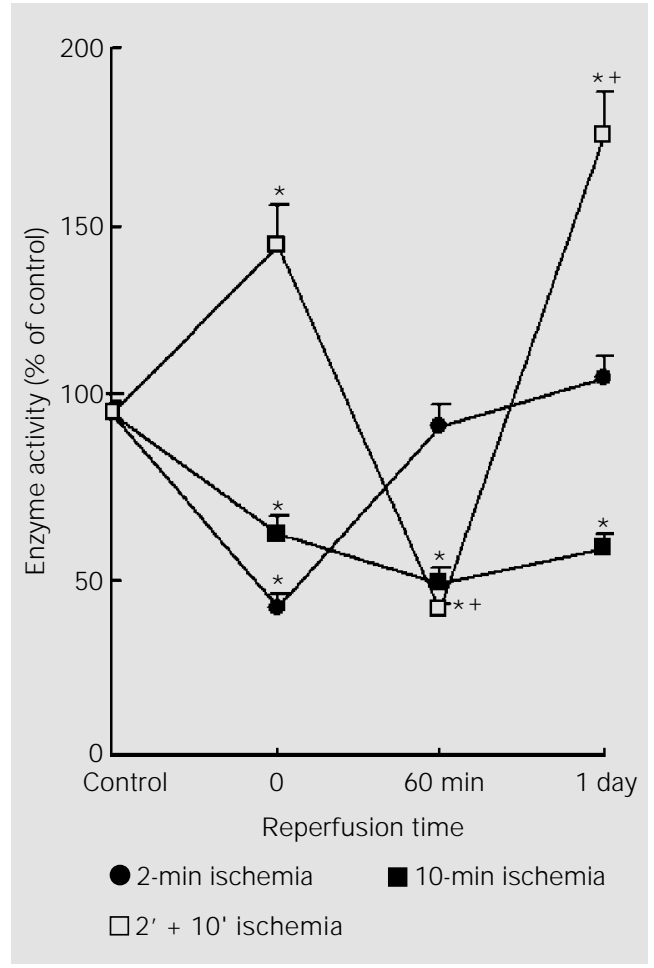

activities of ATP diphosphohydrolase and 5 '-nucleotidase (AMPase) activity, that correspond to $100 \%$, were $11.2 \pm 0.71$ (mean \pm $\mathrm{SEM}, \mathrm{N}=8), 5.9 \pm 0.36($ mean $\pm \mathrm{SEM}, \mathrm{N}=$ 8 ) and $1.8 \pm 0.10($ mean $\pm S E M, N=8) \mathrm{nmol}$ Pi released min $^{-1} \mathrm{mg}$ protein ${ }^{-1}$, respectively. ATP and ADP hydrolysis by ATP diphosphohydrolase was significantly decreased by $40-50 \%$ immediately after 2 or $10 \mathrm{~min}$ of ischemia when compared to sham and control groups (Figures 1 and 2). On the other hand, AMP hydrolysis by 5'-nucleotidase was significantly increased by $30 \%$ after 2 min of ischemia when compared to the corresponding sham and control groups, but was similar to control levels after 10 min of ischemia (Figure 3). When recirculation was allowed, $60 \mathrm{~min}$ of reperfusion after the 2min ischemic episode was enough to bring ATP, ADP and AMP hydrolysis to control levels (Figures 1-3). However, rats submitted to $10 \mathrm{~min}$ of ischemia showed impaired enzymatic activities after both $60 \mathrm{~min}$ and 1 day of reperfusion (Figures 1-3). Table 1 shows impairment up to 30 days.

In an attempt to determine the time for recovery of activity, we studied animals 2, 5, 10 and 30 days after $10 \mathrm{~min}$ of ischemia. As shown in Table 1, we noticed a sustained decrease in ATP diphosphohydrolase activity (ATPase and ADPase) up to 30 days after the event. AMP hydrolysis was significantly increased by 30 and $60 \%$ after 2- and 5-day reperfusion, respectively. Interestingly, ischemic animals submitted to 10 and 30 days of recirculation presented 5'-nucleotidase activity comparable to control rats (Table 1).

\section{Effects of preconditioning to brain ischemia on platelet ATP diphosphohydrolase and 5'-nucleotidase activities}

We next examined the effect of ischemia on the enzyme activities in preconditioned rats. These animals were subjected to a brief ischemic episode $(2 \mathrm{~min})$ inflicted 1 day before $10 \mathrm{~min}$ of ischemia, i.e., they were 
made tolerant to neuronal death caused by the longer ischemic insult. As shown in Figures 1 and 2, there was a $40-50 \%$ increase in ATP and ADP hydrolysis in the preconditioned group $\left(2^{\prime}+10^{\prime}\right)$ when compared to sham and control groups, in contrast with groups submitted to 2 or $10 \mathrm{~min}$ of ischemia alone. There was a marked activation (about $100 \%$ ) of AMP hydrolysis (Figure 3) after the double-ischemic episode.

Interestingly, at 60-min reperfusion after the double-ischemic episode, ATP, ADP and AMP hydrolysis rates (Figures 1-3) were significantly lower than in the respective controls. After one day of reperfusion, the inhibitory effects on ADP and AMP hydrolysis were cancelled. Although ATP hydrolysis was higher when compared to controls at 1 day (Figure 1), preconditioned rats submitted to 2 days of reperfusion showed control levels of activity (enzyme activity $\%$ of control $=106.9 \pm 7.8 \%$, mean $\pm \mathrm{SEM}$, $\mathrm{N}=8$ ). Confirming the trend shown in Figures 2 and 3, ADP and AMP hydrolysis rates in the preconditioned rats were still similar to controls after 2 days of reperfusion (84.6 $\pm 4.5 \%, \mathrm{~N}=7$, and $109.7 \pm 8.6 \%, \mathrm{~N}=8$, respectively).

\section{Discussion}

The main results of the present study are: i) brain ischemia (2 or $10 \mathrm{~min}$ ) inhibited ATP diphosphohydrolase activity from rat blood platelets (Figures 1 and 2), whereas 5'nucleotidase was activated after $2 \mathrm{~min}$ of ischemia and this effect did not occur after a 10-min ischemic episode (Figure 3 ). In contrast, preconditioned rats $\left(2^{\prime}+10^{\prime}\right.$ ischemic episode) showed an increase in both enzyme activities (Figures 1-3). ii) Enzymatic activities changed when recirculation was allowed. Reperfusion of 60 min after 2 min of ischemia caused a return of activities to control levels. However, the inhibition of ATP diphosphohydrolase activity following $10 \mathrm{~min}$ of ischemia was still present after 30 days of reperfusion (Table 1). 5'-Nucleotidase activity was changed by reperfusion after a single 10-min ischemic episode when compared to ischemia without reperfusion (Figure 3 and Table 1). iii) The preconditioned ischemic
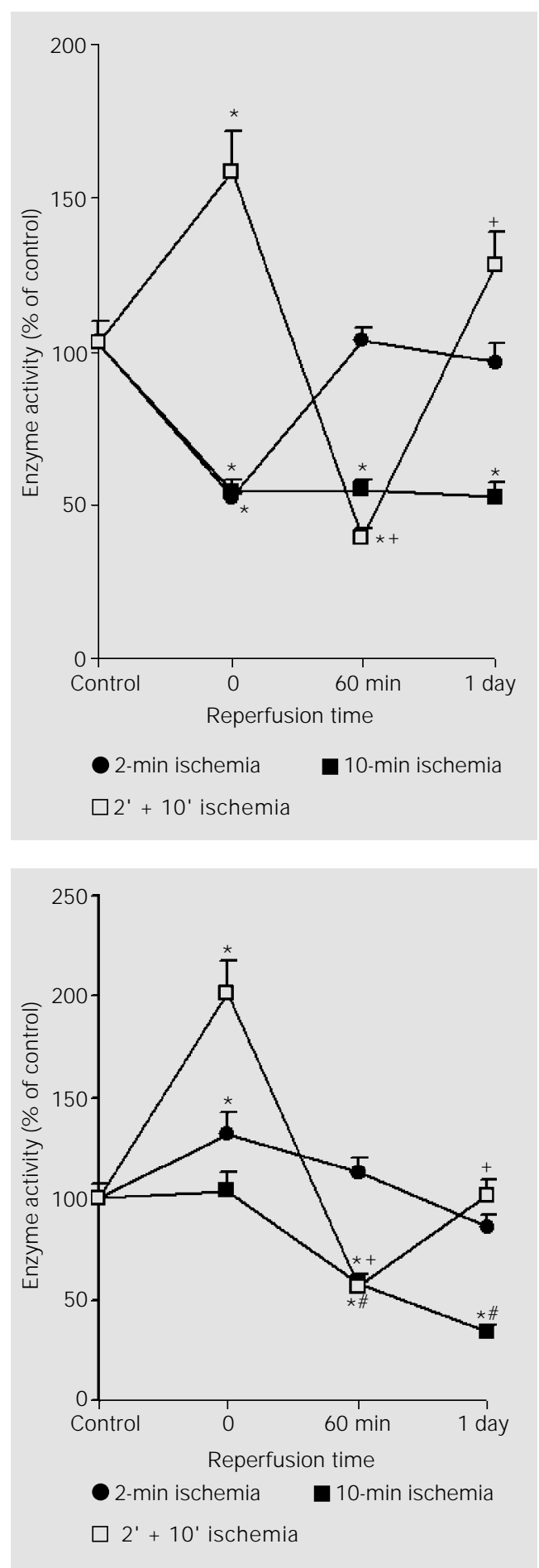

Figure 2 - Activity of platelet ATP diphosphohydrolase (ADPase activity) after brain ischemia (2 and $10 \mathrm{~min}$ ) and ischemic preconditioning $\left(2^{\prime}+10^{\prime}\right)$ followed by reperfusion. Results are expressed as percentage of control activity. Data are reported as means \pm SEM for 6 to 8 different platelet preparations assayed in duplicate. Sham value for ADPase activity was $97.4 \pm$ $10 \%(\mathrm{~N}=6) . * \mathrm{P}<0.05$ compared to control group. ${ }^{+} \mathrm{P}<0.05 \mathrm{com}$ pared to the $2^{\prime}+10^{\prime}$ group without reperfusion (analysis of variance and Duncan test).

Figure 3 - Activity of platelet 5 nucleotidase (AMPase activity) after brain ischemia (2 and 10 $\mathrm{min}$ ) and ischemic preconditioning $\left(2^{\prime}+10^{\prime}\right)$ followed by reperfusion. Results are expressed as percentage of control activity. Data are reported as means \pm SEM for 6 to 8 different platelet preparations assayed in duplicate. Sham value for AMPase activity was $99.5 \pm 9.5 \%(\mathrm{~N}=6)$. $* \mathrm{P}<0.05$ compared to control group. ${ }^{+} \mathrm{P}<0.05$ compared to the $2^{\prime}+10^{\prime}$ group without reperfusion. ${ }^{\#}<0.05$ compared to the 10-min ischemia group without reperfusion (analysis of variance and Duncan test). 
group $\left(2^{\prime}+10^{\prime}\right)$ showed recovery of both enzymatic activities after 2 days of reperfusion, in marked contrast to the altered activity after the single $10 \mathrm{~min}$ of ischemia. Since brain ischemia alters ATP, ADP and AMP hydrolysis by platelets, these results suggest that changes in ATP diphosphohydrolase and 5'-nucleotidase activities should be associated with molecular events that follow ischemia. Nevertheless, since platelet turnover time is approximately 5-9 days (28), the sustained inhibition of ATP diphosphohydrolase activity after $10 \mathrm{~min}$ of ischemia, lasting for 30 days (Table 1), suggests a possible inhibition of enzyme synthesis in the megakaryocytes. However, this interpretation cannot be considered for 5'-nucleotidase activity since it returns to basal values between 5 and 10 days after ischemia.

The fact that preconditioned rats showed activation of both enzyme activities suggests that induced tolerance to brain ischemia might be related to enzymatic modulation for the inhibition of microthrombus formation in the peripheral circulation. In the central nervous system, it has been suggested that upregulation of the enzyme chain hydrolyzing extracellular ATP after transient forebrain ischemia in the rat could play a role in the postischemic control of nucleotide-mediated cellular responses (29). Since platelets are anucleate (28), the possibility of upregulation of the enzymes is excluded. Considering the results of reperfusion after ischemic preconditioning (Figures 1 and 2), and remembering that $10 \mathrm{~min}$ of ischemia caused longterm (30 days) inhibition of ATP diphosphohydrolase activity (Table 1), we suggest that protective mechanisms induced by preconditioning might be associated with the return of enzymatic activity to control levels after 2 days of reperfusion. With respect to 5'-nucleotidase activity, AMP hydrolysis returned to control levels after $2^{\prime}+10^{\prime}$ ischemia (preconditioning) followed by 1 day of reperfusion (Figure 3) while $10 \mathrm{~min}$ of ischemia altered enzyme activity up to 5 days of reperfusion. To our knowledge, this is the first demonstration of a peripheral effect of brain ischemia and ischemic preconditioning involving platelet ecto-enzymes related to adenosine formation.

Preconditioning involves brief periods of ischemia that confer protection against a prolonged ischemic challenge. It is known that $10 \mathrm{~min}$ of transient forebrain ischemia causes massive cell death in the $\mathrm{CA}_{1}$ subfield of the rat hippocampus, while $2 \mathrm{~min}$ of ischemia causes no lesion; however, preconditioning results in $50-60 \%$ protection against cell necrosis $(16,20)$. Athough these studies have clearly demonstrated the effects of preconditioning on the nervous system, the mechanisms underlying such effects have not yet been established. Ytrehus and coworkers (30) have shown that adenosine

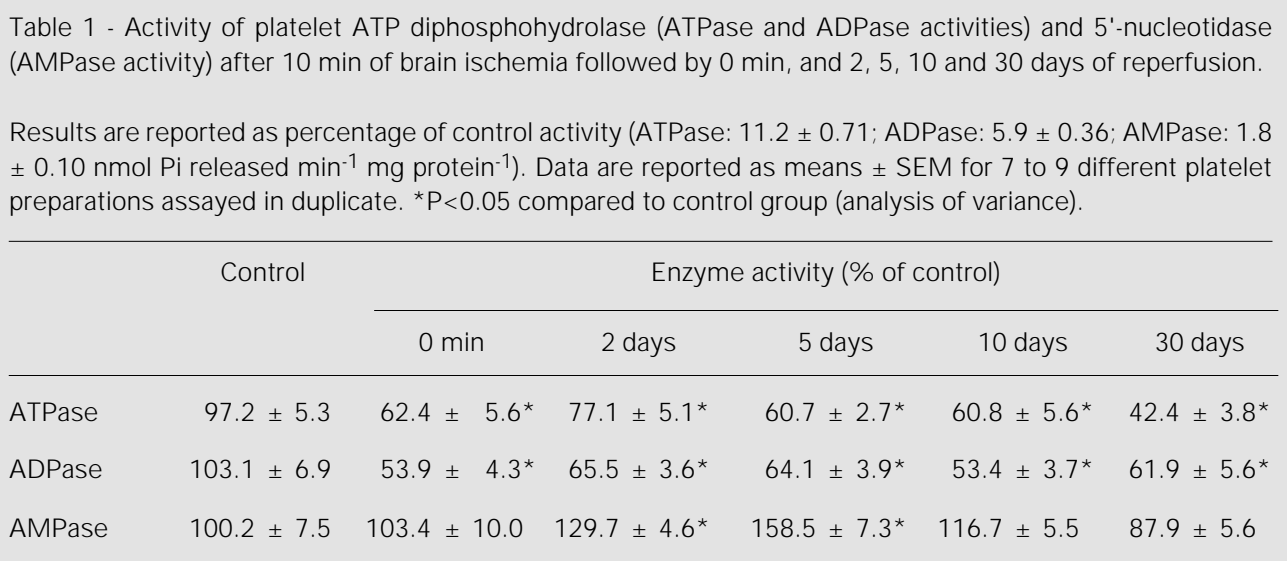


receptors are involved in the beneficial effects of myocardial preconditioning. The observation that platelet 5'-nucleotidase was highly activated after ischemic preconditioning $\left(2^{\prime}+10^{\prime}\right)$ (Figure 3$)$ suggests that adenosine is possibly being formed to bind to its receptors to protect against ischemic injuries. Interestingly, ATP and ADP hydrolysis by ATP diphosphohydrolase was increased after the ischemic preconditioning (Figures 1 and 2). These data suggest that during brain ischemic preconditioning, platelet ATP diphosphohydrolase and 5'-nucleotidase are probably modulated to inhibit platelet aggregation and microthrombus formation when ADP is hydrolyzed and adenosine is generated. Furthermore, data from animals reperfused after ischemic preconditioning suggest an interaction between enzyme activities and the protective effect of brain preconditioning against a longer period of ischemia $(10 \mathrm{~min})$ and reperfusion. As reported, ATP diphosphohydrolase activity was not inhibited after ischemic preconditioning followed by 1 or 2 days of reperfusion as it was after $10 \mathrm{~min}$ of ischemia. In the preconditioned group $\left(2^{\prime}+10^{\prime}\right)$ submitted to 1 or 2 days of reperfusion, 5'-nucleotidase activity was not altered when compared to controls, but was altered at the onset of reperfusion. Thus, changes in these enzyme activities associated with brain ischemia and reperfusion were prevented by preconditioning.

The concentration of brain extracellular adenosine increases during ischemia, and this is believed to confer cytoprotection (31). Functions mediated by adenosine receptors such as vasodilation (32), inhibition of $\mathrm{Ca}^{2+}$ influx in cells populating the ischemic area (33), inhibition of the release of neurotransmitters such as glutamate (33) and inhibition of platelet aggregation (15) may account for the beneficial effect of adenosine. The nucleoside also affords protection against ischemic reperfusion injuries associated with significant increases in reactive oxygen species (30).
The activation of 5'-nucleotidase activity after 2 min of ischemia (Figure 3), after the ischemic preconditioning $\left(2^{\prime}+10^{\prime}\right)$ (Figure 3 ) and after $10 \mathrm{~min}$ of ischemia followed by 2- and 5-day reperfusion (Table 1) may correspond to a mechanism that leads to an increase of adenosine levels in the platelet microenvironment. Interestingly, in these situations, except for the ischemic preconditioning group, ATP and ADP hydrolysis by ATP diphosphohydrolase was decreased. These results may indicate that when ATP diphosphohydrolase is inhibited after brain ischemia, ADP is present at sufficient concentrations to induce platelet aggregation even when adenosine is produced. One might propose that the inhibition of ATP diphosphohydrolase after brain ischemia would facilitate ischemic injury. Our results are in agreement with studies that have shown platelet aggregability and in vivo platelet deposition in the circulation of patients with ischemic cerebrovascular disease (21) and thromboembolic events after transient global ischemia in rats (34) and sheep (35). These effects have been interpreted as a consequence of platelet exposure to an ischemic microvascular bed subsequent to an early and evolving endothelial injury (35). Probably, the phenomenon of preconditioning to brain ischemia may correspond to a protective mechanism when both ATP diphosphohydrolase and 5'-nucleotidase activities are increased (Figures 1-3). As regards the effect of $10 \mathrm{~min}$ of ischemia followed by 10 or 30 days of reperfusion, AMP hydrolysis was not altered when compared to controls (Table 1), suggesting that it also occurs to maintain adenosine levels.

In view of such clear effects, we are tempted to offer possible interpretations for the peripheral modulation of platelet enzymatic activities induced by brain ischemia and ischemic preconditioning. The first possibility is a change in the characteristics of the active site or in its conformation by a modulatory factor not yet known, that may 
be related to ischemic preconditioning or brief ischemic stages. The second involves environmental changes caused by degradation of membrane phospholipids surrounding enzyme molecules, generating free radical species during ischemia. We have recently demonstrated that free radicals cause in vitro inhibition of ATP diphosphohydrolase activity from rat platelets (36) and synaptic plasma membrane (37). Furthermore, nitrosylation or phosphorylation through an interaction with nitric oxide was recently reported to affect the activity of membranebound proteins $(38,39)$. Node et al. (40) have shown the activation of ecto-5'-nucleotidase by phosphorylation and its role in ischemic tolerance in the canine heart. Considering our results, the relevance of these suggestions should be examined in future experiments.

The fact that brain ischemia, reperfusion and preconditioning can induce peripheral alterations in ecto-enzymes involved in nucleotide metabolism, similarly to what occurs in the nervous system (20), is the most important feature of our results. We are tempted to speculate that mechanisms operating in the modulation of ATP diphosphohydrolase activity in the ischemic hippocampus (20) may be similar to those operating in platelets. Our understanding is that changes in platelet ecto-enzyme modulation and enhanced production of adenosine are physiological responses aimed at the regulation of microthrombus formation, an after-effect of brain ischemia $(21,34,35)$.

In summary, we have shown that brain ischemia alters ATP diphosphohydrolase and 5'-nucleotidase activities from rat blood platelets. The present findings support the hypothesis that protection by ischemic preconditioning is probably mediated by enhanced hydrolysis of ATP, ADP and AMP and production of adenosine through the activation of these ecto-enzymes. Since all enzymatic activities studied and adenosine receptors are located on the platelet membrane, the adenosine putatively produced would act in the same environment. In any case, we believe that modulation of such enzymes and the consequent changes of platelet ATP, ADP and AMP hydrolysis as a peripheral effect of brain ischemia, reperfusion and preconditioning should be related to the regulation of microthrombus formation and vascular tissue oxygen supply since ADP aggregates platelets (13) and adenosine is an inhibitor of platelet aggregation (15).

\section{References}

1. Meyerhof O (1945). The origin of the reaction of Harden and Young in cell-free alcoholic fermentation. J ournal of Biological Chemistry, 157: 105-109.

2. Komoszynski MA (1994). Apyrases-enzymes involved in the control of nucleotides level in cells and tissues. Advanced Biochemistry, 40: 174-180.

3. Najjar SM, Acilli D, Philippe N, J emberg J , Margolis R \& Taylor SI (1993). pp120/ectoATPase, an endogenous substrate of an insulin receptor tyrosine kinase, is expressed as two variably spliced isoforms. J ournal of Biological Chemistry, 268: 1201-1206.

4. Frassetto SS, Dias RD \& Sarkis J J F (1993). Characterization of an ATP diphosphohydrolase activity (apyrase, EC 3.6.1.5) in rat blood platelets. Molecular and Cellular Biochemistry, 129: 47-55.

5. Frassetto SS, Dias RD \& Sarkis J J F (1995). Inhibition and kinetic alterations by excess free ATP and ADP of the ATP diphosphohydrolase activity (EC 3.6.1.5) from rat blood platelets. Biochemistry and Molecular Biology International, 35: 499-506.

6. Bergamini C \& Grazi E (1980). Human platelets 5'-nucleotidase: a cell membrane ecto-enzyme with a possible regulatory role in the aggregation reaction. Italian J ournal of Biochemistry, 29: 273-288.

7. Pilla C, Emanuelli T, Frassetto SS, Battastini AMO, Dias RD \& Sarkis JJF (1996). ATP diphosphohydrolase activity (apyrase, EC 3.6.1.5) in human blood platelets. Platelets, 7: 225-230.

8. Battastini AMO, RochaJ BT, Barcellos CK Dias RD \& Sarkis J J F (1991). Characterization of an ATP diphosphohydrolase (EC 3.6.1.5) in synaptosomes from cerebral cortex of adult rats. Neurochemical Research, 16: 1303-1310.

9. Sarkis J J F \& Salto C (1991). Characterization of a synaptosomal ATP diphosphohydrolase from the electric organ of Torpedo marmorata. Brain Research Bulletin, 26: 871-876.

10. Battastini AMO, Oliveira EM, Moreira CM, Bonan CD, Sarkis JJ F \& Dias RD (1995). Solubilization and characterization of an ATP diphosphohydrolase (EC 3.6.1.5) from rat brain synaptic plasma membranes. Biochemistry and Molecular Biol- 
ogy International, 37: 209-219.

11. Oliveira EM, Battastini AMO, Meirelles MNL, Moreira CM, Dias RD \& Sarkis J J F (1997). Characterization and localization of an ATP diphosphohydrolase activity (EC 3.6.1.5) in sarcolemmal membrane from rat heart. Molecular and Cellular Biochemistry, 170: 115-123.

12. Bumstock $G$ (1990). Dual control of local blood flow by purines. Annals of the New York Academy of Sciences, 603: 31-45.

13. Colman RW (1990). Aggregin: a platelet $A D P$ receptor that mediates activation. FASEB J ournal, 4: 1425-1435.

14. Engler RL (1991). Adenosine. The signal of life? Circulation, 84: 951-954.

15. Kitakaze M, Hori M, Sato H, Takashima S, Inoue M, Kitabatake A \& Kamada T (1991). Endogenous adenosine inhibits platelet aggregation during myocardial ischemia in dogs. Circulation Research, 69: 14021408.

16. Schmidt-Kastner R \& Freund TF (1991). Selective vulnerability of the hippocampus in brain ischemia. Neuroscience, 40 : 599-636.

17. Kirino T, Tsujita $Y$ \& Tamura A (1991). Induced tolerance to ischemia in gebril hippocampal neurons. J ournal of Cerebral Bood Flow and Metabolism, 11: 299-307.

18. Kitakaze $M$, Minamino $T$, Node $K$, Komamura K \& Hori M (1996). Activation of ecto-5'-nucleotidase and cardioprotection by ischemic preconditioning. Basic Research in Cardiology, 91: 23-26.

19. Losano G, Gattullo D \& Pagliaro P (1996). Myocardial, neural and vascular aspects of ischemic preconditioning. Life Sciences, 59: 1185-1192.

20. Schetinger MRC, Barcellos $C K$, Barlem $A$, Zwestch G, Gubert A, Bertuol C, Arteni N, Dias RD, Sarkis J J F \& Netto CA (1994). Activity of synaptosomal ATP diphosphohydrolase from hippocampus of rats tolerant to forebrain ischemia. Brazilian J ournal of Medical and Biological Research, 27: 1123-1128.

21. Isaka $Y$, Kimura K, Uehara A, Hashikawa K, Mieno M, Matsumoto M, Handa N, Nakabayashi S, Imaizumi M \& Kamada T
(1989). Platelet aggregability and in vivo platelet deposition in patients with ischemic cerebrovascular disease. Evaluation by indium-111-platelet scintigraphy. Thrombosis Research, 56: 739 (Abstract).

22. Tanahashi N, Tomita M, Kobari M, Takeda H, Yokoyama M, Takao M \& Fukuuchi Y (1996). Platelet activation and erythrocyte aggregation rate in patients with cerebral infarction. Clinical Hemorheology, 16: 497-505.

23. Netto CA, Hodges $H$, Sinden J D, Le Peillet E, Kershaw T, Sowinski P, Meldrum BS \& Gray J A (1993). Effects of fetal hippocampal field grafts on ischemic-induced deficits in spatial navigation in the water maze. Neuroscience, 54: 69-92.

24. Hantgan RR (1984). A study of the kinetics of ADP-triggered platelet shape change. Blood, 64: 896-906.

25. Nishio H, Takeshita K, Okugawa $K \&$ Segawa T (1987). Effect of concanavalin $A$ on $5^{\prime}$-nucleotidase activity of rabbit blood platelets. J apanese J ournal of Pharmacology, 43: 230-233.

26. Chan KM, Delfert D \& J unger KD (1986). A direct colorimetric assay for $\mathrm{Ca}^{2+}$ ATPase activity. Analytical Biochemistry, 157: 375-378.

27. Bradford MM (1976). A rapid and sensitive method for the quantification of microgram quantities of protein utilizing the principle of protein dye binding. Analytical Biochemistry, 72: 248-254.

28. Holmsen H (1985). Nucleotide metabolism of platelets. Annual Review of Physiology, 47: 677-690.

29. Braun N, Zhu Y, Krieglsein J, Culmsee $C$ \& Zimmermann $\mathrm{H}$ (1998). Upregulation of the enzyme chain hydrolyzing extracellular ATP after transient forebrain ischemia in the rat. J ournal of Neuroscience, 18: 4891-4900.

30. Ytrehus K, Liu Y \& Downey J M (1994). Preconditioning protects ischemic rabbit heart by protein kinase $\mathrm{C}$ activation. American J ournal of Physiology, 266: $\mathrm{H} 1145-\mathrm{H} 1152$.

31. Ramkumar V, Nie Z, Rybak LP \& Maggirwar SB (1995). Adenosine, antioxi- dant enzymes and cytoprotection. Trends in Pharmacological Sciences, 16: 283-285.

32. Phillis J W (1989). Adenosine in control of cerebral circulation. Cerebrovascular and Brain Metabolism Reviews, 1: 26-54.

33. Rudolphi KA, Schubert P, Parkinson FE \& Fredholm BB (1992). Adenosine and brain ischemia. Cerebrovascular and Brain Metabolism Reviews, 4: 346-369.

34. Dietrich WD, Danton G, Hopkins AC \& Prado R (1999). Thromboembolic events predispose the brain to widespread cerebral infarction after delayed transient global ischemia in rats. Stroke, 30: 855-861.

35. Littleton-Kearney MT, Hurn PD, Kickler TS \& Traystman RJ (1998). Incomplete global cerebral ischemia alters platelet biology in neonatal and adult sheep. American J ournal of Physiology, 274: H1293-H1300.

36. Frassetto SS, Dias RD \& Sarkis J J F (1997). Free radical-induced inhibition of ATP diphosphohydrolase activity (EC 3.6.1.5) from rat blood platelets. Biochemistry and Molecular Biology International, 41: 161168.

37. Vietta M, Frassetto SS, Battastini AMO, Klein AB, M oreira C, Dias RD \& Sarkis J J F (1996). Sensitivity of ATPase-ADPase activities from synaptic plasma membranes of rat forebrain to lipid peroxidation in vitro and the protective effect of vitamin $\mathrm{E}$. Neurochemical Research, 21: 299-304.

38. Nolte $C$, Eigenthaler $M$, Pschanzenbacher P \& Walter U (1991). Endothelial cell-dependent phosphorylation of a platelet protein mediated by CAMP- and CGMP-elevating factors. J ournal of Biological Chemistry, 266: 14808-14812.

39. Siegfried $G$, Amiel $C \& \&$ Friedlander $G$ (1996). Inhibition of ecto-5'-nucleotidase by nitric oxide donors. J ournal of Biological Chemistry, 271: 4659-4664.

40. Node K, Kitakaze M, Minamino T, Tada M, Inoue M, Hori M \& Kamada T (1997). Activation of ecto-5'-nucleotidase by protein kinase $C$ and its role in ischaemic tolerance in the canine heart. British J ournal of Pharmacology, 120: 273-281. 